\title{
Armas de fuego sin frontera. El caso de Baja California, México (2013-2020)
}

\section{Firearms without frontiers. Baja California, Mexico case study (2013-2020)}

Gerardo Hernández a* (iD https://orcid.org/0000-0003-2803-6905 Zulia Orozco Reynoso (i) https://orcid.org/0000-0002-5796-4164

a Universidad Autónoma de Baja California, Instituto de Investigaciones Sociales, Mexicali, México, correo electrónico: ghernandez48@uabc.edu.mx; zulia.orozco@uabc.edu.mx

\section{Resumen}

El objetivo de la investigación es analizar el tráfico de armas de fuego de Estados Unidos hacia México y su correlación con la violencia homicida en el estado fronterizo de Baja California en el periodo 2013-2020. La metodología es inductiva debido a que observa y registra la información disponible de la incautación de armas. También es exploratoria porque el tráfico de armas de fuego se ha mantenido en la discusión pública pero poco se ha analizado desde la perspectiva

Recibido el 3 de mayo de 2021.

Aceptado el 8 de noviembre de 2021.

Publicado el 17 de noviembre de 2021.

${ }^{*}$ Autor para correspondencia: Gerardo Hernández. Correo electrónico: ghernandez48@uabc.edu.mx

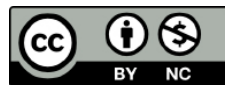

Esta obra está protegida bajo una Licencia Creative Commons Atribución-NoComercial 4.0 Internacional. teórica del diseño de la agenda e implementación de las políticas públicas. Los resultados plantean que las lagunas en el marco normativo del control de armas de fuego en México incentivan oportunidades para que la delincuencia organizada trafique armas generando espirales de violencia en territorios como Baja California. Existen limitaciones en la disponibilidad de información, pero la perspectiva teórica utilizada permite desarrollar y comprobar la hipótesis de la investigación.

Palabras clave: armas de fuego, delincuencia organizada, instituciones, tráfico de armas, México, Estados Unidos.

\section{Abstract}

This research aims to analyze firearms trafficking from the United States to Mexico and its correlation with homicidal violence in the border state of Baja California during 2013-2020. The methodology is inductive because it observes and registers the available data on weapon seizure. It is also exploratory because firearms trafficking has remained in public discussion. Still, little has been analyzed from the theoretical perspective, from the public policy agenda design and its' implementation. The results suggest that regulatory gaps in the legal firearms control framework in Mexico encourage opportunities for organized crime to traffic weapons, generating spirals of violence in territories

CÓMO CITAR: Hernández, G. \& Orozco Reynoso, Z. (2021). Armas de fuego sin frontera. El caso de Baja California, México (20132020) [Firearms without frontiers. Baja California, Mexico case study (2013-2020)]. Estudios Fronterizos, 22, e082. https://doi. org/10.21670/ref.2119082 
such as Baja California. There are limitations in the availability of information, but the theoretical perspective allows the research hypothesis to be developed and tested.

Keywords: firearms, organized crime, institutions, firearms trafficking, Mexico, United States of America.

\section{Introducción}

El fenómeno del tráfico de armas es uno de los principales retos que enfrentan los gobiernos a nivel global por sus implicaciones en las políticas de seguridad. En el Estudio Mundial sobre Tráfico de Armas de Fuego se advierte que, en 80 países, entre 2016 y 2017, se han incautado más de 500000 armas de fuego. Sin embargo, las cifras reportadas podrían ser solo una parte de la magnitud total del problema, debido al subregistro en la detección oportuna y eficiente del tráfico — hormiga - de armas; cabe señalar que, en América Latina, en $75 \%$ de los homicidios en la región está involucrada un arma de fuego (Oficina de las Naciones Unidas contra la Droga y el Delito [unODC], 2020, pp. 14-19; Goodwin, 2020).

Este panorama muestra que el trasiego de armas conlleva un desafío para el diseño de la agenda e implementación de políticas públicas en los Estados nación. México es el país con la mayor cantidad de fusiles decomisados y la tasa de delitos cometidos por armas se incrementó a más del doble, al pasar de 13.6 por cada 100000 habitantes en 2015 a 29.6 en 2019 (Institute for Economics \& Peace [IEP], 2020, p. 4; UNODC, 2020, p. 14). Lo anterior se ha traducido en espirales de violencia inusitada en regiones estratégicas como Baja California. La importancia de este territorio localizado en el noroeste de México radica no solo por ser frontera con Estados Unidos sino también por ser una entidad que se ha caracterizado por los flujos migratorios tanto a nivel interno como internacional. Entre 2015 y 2020 llegaron a vivir al estado 211416 personas y en ese mismo periodo salieron del estado a vivir a otro país 26600 personas, de las cuales 92 de cada 100 se fueron a Estados Unidos (Instituto Nacional de Estadística y Geografía [Inegi], 2021a). El estado también ha resultado estratégico para los grupos de la delincuencia organizada que trafican estupefacientes, personas, drogas y armas de fuego.

El objetivo del presente documento es analizar el tráfico de armas de fuego de Estados Unidos hacia México y su correlación con la violencia homicida en el noroeste del país, específicamente Baja California. La hipótesis plantea que las lagunas normativas en el diseño institucional y la implementación de la política de la Ley Federal de Armas de Fuego y Explosivos (LFAFE) en México incentivan oportunidades para que la delincuencia organizada trafique armas de fuego hacia México lo que genera espirales de violencia en territorios estratégicos como Baja California. Asimismo, la narrativa gubernamental y de la agenda sistémica en México ha responsabilizado al gobierno estadounidense por la facilidad al acceso de armas sin asumir las fallas en el diseño de la política de armas de fuego.

El artículo se divide en cuatro secciones. En la primera se plantean los referentes teóricos del diseño de la agenda e implementación de las políticas públicas. En la segunda parte se analiza el diseño de la Ley Federal de Armas de Fuego y Explosivos y el Código Nacional de Procedimientos Penales para identificar lagunas normativas, así como los actores involucrados en su implementación. En la tercera sección se exponen, a 
través de gráficas y mapas, las consecuencias regionales del tráfico de armas de fuego en Baja California y a nivel nacional. Asimismo, se exponen los retos a los que se enfrenta el Estado mexicano y la región de Baja California ante el fenómeno de las armas de fuego. En la última sección se encuentran las conclusiones.

\section{Metodología}

El estudio toma como referencia el estado de Baja California en el periodo 2013-2020, es decir, la administración estatal del gobernador, Francisco Vega de Lamadrid (20132019), y el primer año de gobierno de Jaime Bonilla Valdez (2019-2021). El análisis es inductivo porque parte de la observación y registro - a través de tablas, gráficas y mapas- de la información disponible de la incautación de armas de fuego en el país. Asimismo, se comparan y analizan las consecuencias en materia de homicidios dolosos relacionados con la disponibilidad de armas ilegales. Esto permite exponer el nivel de violencia en la región fronteriza de Baja California, México, y California, Estados Unidos, para hacer hincapié — desde el enfoque teórico de las políticas públicas-en las fortalezas institucionales para contener la violencia homicida en cada una de las regiones involucradas en el tráfico de armas.

El artículo es exploratorio porque el estudio del tráfico de armas de fuego se ha mantenido en la discusión pública pero poco se ha analizado desde la perspectiva teórica del diseño de la agenda e implementación de las políticas públicas. Además, la falta de información y transparencia refleja la importancia de indagar en el tema debido a que el problema de las armas de fuego no solo responde a una lógica de economía criminal sino a un fenómeno trasnacional en la cual los gobiernos desde las políticas públicas tienen que hacer frente.

Las fuentes de información son cualitativas, cuantitativas y cartográficas, la cuales provienen de solicitudes de información disponibles en el portal de la Secretaría de la Defensa Nacional (Sedena), la Cámara de Diputados Federal en México, la Fiscalía General del Estado de Baja California (FGEBC), del Secretariado Ejecutivo del Sistema Nacional de Seguridad Pública (sESnSP), el Instituto Nacional de Estadística y Geografía (Inegi), la Encuesta Nacional de Seguridad Pública Urbana (ENSU), los informes de gobierno a nivel federal y local, reportes académicos y de organizaciones civiles especializadas en México y Estados Unidos, así como de fuentes hemerográficas.

\section{Las instituciones importan. Diseño de la agenda pública e implementación de políticas}

El diseño de la agenda pública generalmente atrae una considerable atención o conocimiento del público y es percibida como cuestiones que recaen dentro de las competencias de alguno de los rubros gubernamentales (Cobb et al. 1976, p. 127). Por su parte, Ortega Pérez y Ruiz Seisdedos (2005, p. 117) mencionan que el problema existe en la agenda pública en la medida en que los poderes públicos lo consideran como una situación sobre la que hay que actuar. Asimismo, el establecimiento de la agenda pública ha sido relacionado con el desempeño de los medios de comunicación 
debido a que se argumenta que son estos quienes fijan la agenda (agenda-setting) (McCombs \& Shaw, 1972, pp. 176-187; Beltrán \& Cinta, 1998, pp. 295-327; Andrews \& Caren, 2010, pp. 841-866; Tamayo \& Carrillo Barroso, 2005, pp. 658-681; Henry \& Gordon, 2001, pp. 157-177). Esto es importante debido al inexorable vínculo que existe entre agenda pública y políticas públicas debido a que la primera juega un rol determinante en el diseño de las segundas.

En el caso de México, el tema de las armas de fuego, sus consecuencias en el contexto de violencia homicida en el país, la relación con la delincuencia organizada, así como la relación bilateral con Estados Unidos por la regulación de armas, no necesariamente ha unificado una agenda que incida en la política pública para hacer frente al fenómeno del trasiego de armas de manera efectiva (Déziga, 2020; Osorio, 2020; González et al., 2017, pp. 2861-2872; Coss Nogueda, 2005). Una explicación a lo anterior se encuentra en lo que Cobb y Elder plantean, es decir, la existencia de dos tipos de agendas, la sistémica y la institucional. La primera hace referencia a todos los temas percibidos por la comunidad política que merecen la atención pública y de la autoridad gubernamental. La segunda se define como la serie de puntos explícitamente señalados para recibir la consideración activa de los tomadores de decisiones (1972, pp. 85-86).

Esta dicotomía se hace porque el proceso político puede no ser tan abierto como para permitir que todos los problemas atraigan la atención política. El proceso de establecimiento de la agenda puede estar bastante sesgado y favorecer determinados problemas e intereses (Parsons, 2007, p. 118). En otras palabras, debido a que la agenda tiene lugar como resultado de la expansión de un tema desde un público interesado e informado, no se puede dejar de lado el carácter fuertemente político que se presenta entre actores - gubernamentales y no gubernamentales- que se involucran en el juego político de la construcción de aquella, pues, como ya se mencionó, buscan posicionar sus intereses en la discusión pública (Ortega Pérez \& Ruiz Seisdedos, 2005, pp. 123-124; Parsons, 2007, p. 159).

Esta variabilidad a la que se alude es lo que conlleva a que los que controlan las instituciones sean quienes, dentro de la complejidad del proceso de las políticas públicas, decidan de acuerdo con el grado de presión recibida qué asuntos son los que arribarán a la agenda pública. Esto ya fue advertido por Schattscheider quien señala que: "Todas las formas de organización política están sesgadas a favor de la explotación de ciertos tipos de conflicto y la supresión de otros, pues organización significa movilización de sesgos" (citado en Parson, 2007, p. 157). De manera más específica,

Los arreglos o estructuras institucionales habilitantes o inhibidoras de participantes, tiempos y formas de participación; determinan el conjunto de actores que tienen autoridad y capacidad para llevar un asunto de interés sin importar su origen-al estadio de su procesamiento. (Casar \& Maldonado, 2010, p. 227)

Aun con esto, otro reto al que se enfrentan las políticas públicas es la implementación de las mismas, sobre todo, ante un problema como el del trasiego de armas. Máxime porque las políticas no solo tienen lugar en los sistemas políticos nacionales, sino también en un sistema mundial (Parsons, 2007, p. 263). De manera sucinta, hay temas en la agenda política nacional que están vinculados a cuestiones internacionales, como el bienestar económico, las drogas — tráfico de armas de fuego- y el medio ambiente; la interacción de los Estados nación es más amplio; los Estados nación tienen 
menos control de la agenda; los cambios pueden abarcar otros temas y problemas de la agenda; la agenda de las políticas públicas puede ser mundial, pero la toma de decisiones y la implementación están arraigadas en el ámbito de lo nacional (McGrew \& Lewis, 1992, p. 317).

Lo antepuesto, y en relación con el control de armas de fuego, se relaciona con el gran número de actores gubernamentales — cámaras legislativas, gobierno, administración y burocracia, grupos de interés, partidos políticos, grupos de expertosinvolucrados no solo en la formación de la agenda, sino también con los actores no gubernamentales que están a favor y en contra de la libre portación de armas de fuego. Dentro de estos se encuentran parte de la sociedad mexicana proclive a la libre portación de armas de fuego en sus vehículos o negocios, así como las organizaciones civiles que están en contra de cualquier propuesta a favor del acceso de los ciudadanos a la portación de armas de fuego (Centro de Estudios Sociales y de Opinión Pública [CESOP], 2016, p. 7; Imco Staff, 2016). ${ }^{1}$ De igual manera, dentro de estos actores no gubernamentales se encuentra la delincuencia organizada. Este agente criminal posee una marcada dimensión trasnacional, alta capacidad de adaptación, así como una fuerte especialización en los ámbitos específicos de los mercados ilegales, una de ellas el tráfico de armas de fuego (Rojas Aravena, 2008, pp. 97-98). Esta presencia de la delincuencia organizada, de acuerdo con Andreas, se debe en gran medida a lo inevitable de la liberalización de los mercados internacionales (2004, pp. 641-652), lo cual a la par de los mercados ilegales ha significado grandes desafíos para los frágiles Estados nación, quienes son los que deben definir la agenda pública para instrumentar políticas ante problemas como la violencia homicida relacionada con el tráfico de armas de fuego en sus territorios.

La fragilidad institucional aludida y de la cual se sirve la delincuencia organizada se caracteriza por los altos niveles de violencia política; cambios mayores recientes en sus instituciones políticas; un importante grado del uso de la fuerza estatal en los asuntos de política doméstica; la policía cumple importantes roles políticos en la relación cotidiana con los ciudadanos; importantes conflictos políticos sobre la ideología que debe emplearse para organizar al Estado; carencia de una clara jerarquía, explícita y realmente operante, de la autoridad política; alto grado de control estatal sobre los medios de comunicación; presencia de una clase media urbana proporcionalmente pequeña respecto al resto de la población (Buzan, 1988, pp. 20-21).

Esto es importante considerarlo porque la implementación de las políticas es influida por lo fuerte que es un Estado y sus instituciones, así como de los intereses de los diferentes actores que intervengan, es decir, las políticas públicas no son algo fijo, por el contrario, son variables que se modifican, sobre todo en su implementación, en el transcurso del tiempo (Méndez Martínez, 2015, p. 131; Medellín Torres, 2004, pp. 5-56). Esto es independiente de que la autoridad sea quien decida qué política se instrumentará. Por tal motivo, y como plantea Merino, si una organización tiene recursos escasos y está obligada por el marco normativo a realizar procedimientos

\footnotetext{
1 De acuerdo con la encuesta Seguridad y Participación Ciudadana realizada por la Cámara de Diputados en $2016,47 \%$ de los mexicanos está a favor de portar armas en su vehículo o tenerlas en sus negocios. Por otra parte, las organizaciones civiles que se han manifestado en contra del libre acceso a las armas por los ciudadanos son: Cauce Ciudadano; Causa en Común; Consejo Cívico de Instituciones de Nuevo León A. C.; Instituto Mexicano para Competitividad A. C.; Instituto para la Seguridad y la Democracia, A. C.; México Evalúa, Centro de Análisis de Políticas Públicas, A. C.; México, ¿Cómo Vamos?
} 
derivados de políticas tan diversas como complejas, no podrá cumplir sus propósitos o, al menos, no lo hará con la misma eficacia (Merino, 2016, p. 3). Lo anteriormente expuesto se puede apreciar con el diseño de la política pública para enfrentar el trasiego de armas de fuego en México, así como sus repercusiones a nivel nacional y fronterizo con Estados Unidos y la región noroeste de México, específicamente en Baja California.

\section{Análisis normativo de la política en materia de armas en México}

En 1972, el presidente Luis Echeverría Álvarez (1970-1976) declaró que para reforzar la seguridad colectiva se promulgaba la Ley Federal de Armas de Fuego y Explosivos (LFAFE) y su reglamento. Lo anterior, en el contexto de "[...] la actividad de ciertos grupos que pretendían crear un clima de zozobra por medio de asaltos, secuestros y otras tácticas terroristas" (Cámara de Diputados, 2006, p. 73). Esto es importante mencionarlo porque hasta la década de 1980 la delincuencia organizada no figuraba como un actor -no gubernamental - que influyera en la agenda pública de las administraciones federales. Sin embargo, pese a la narrativa gubernamental, esto no significó que la delincuencia organizada no tuviera presencia en el territorio nacional con el mismo grado de violencia cualitativa con el que actualmente se conoce (Astorga, 2015, pp. 27-108; Lajous \& Piccato, 2018).

Cuando la delincuencia organizada dedicada al tráfico de drogas empieza a tomar relevancia en la agenda pública — a la par de la liberalización económica en el país en la década de 1980 - el Estado mexicano evidenció vacíos normativos y de control territorial ante un fenómeno criminal que iba en ascenso. Se hace alusión a esto porque el Artículo 4 de la LFAFE señala que es la Sedena quién deben tener el control de armas de fuego en el país a través del Registro Federal de Armas (Cámara de Diputados, 2021c, p. 1). No obstante, de acuerdo con las solicitudes de información disponibles en el portal de la Sedena, la institución empezó a contabilizar las armas de fuego a partir de 1990, es decir, 18 años después de la entrada en vigor de la política pública (Sedena, 2014a).

Desde la perspectiva teórica utilizada, el hecho de que la implementación de una política pueda estar bastante sesgada y favorezca a determinados problemas e intereses conlleva a consecuencias no intencionadas - por ejemplo, a la consolidación de las estructuras de grupos criminales-, y a que los actores involucrados en su implementación no necesariamente se sumen a los objetivos de la misma. Esto se alude debido a que la LFAFE estipula en los artículos 2 y 3 que además del presidente de la república, la Secretaría de Gobernación y la Sedena, también las autoridades de los estados, Ciudad de México y municipios son los encargados de instrumentar la regla (Cámara de Diputados, 2021c, p. 1).

Sin embargo, titulares de la Sedena han acusado falta de coordinación y compromiso - para instrumentar la política- por los gobernadores, municipios y fiscalías. Esto debido al escaso control sobre el armamento utilizado por las corporaciones policiales en los estados y municipios, pérdida de armamentos y faltantes de cartuchos no justificados (Flores, 2020; Adame, 2021). Durante la administración federal 20062012, el secretario de la Defensa Nacional, Guillermo Galván Galván, declaró que los gobernadores tenían escaso control del armamento a su cargo. Aseguró que se habían 
"encontrado armas que nunca fueron compradas o asimiladas por las diferentes entidades federativas, y lo mismo son cuernos de chivo, M15, M16 y no hay por dónde saber cómo llegaron esas armas" (Coss Nogueda, 2005, p. 14).

En 2005, se estimó que en el país había aproximadamente 4492692 de armas, de igual manera, se informó que existía duplicación de datos, registros incompletos que dificultan saber con certeza cuántas armas circulan en el país (Coss Nogueda, 2005, p. 13). Se hace hincapié en los actores subnacionales porque desde la promulgación de la LFAFE, como se mencionó en párrafos anteriores, la delincuencia organizada no figuraba en la agenda pública nacional debido a que la descentralización del poder político trasladó muchos de los problemas de la agenda hacia los gobiernos subnacionales. En este sentido, los gobernadores - a la par de que en el país se daba la liberalización económica y se transitaba a la democracia-consolidaron sus enclaves autoritarios, dentro de los cuales incluía el control político y la delincuencia organizada en sus territorios (Gibson, 2007, pp. 168-169; Gervasoni, 2011, p. 584; Hernández, 2020, pp. 419-420). ${ }^{2}$

Este tipo de equilibrios políticos a nivel subnacional ocasionó que los actores no gubernamentales, como la delincuencia organizada, para mantener sus actividades criminales - tráfico de drogas, personas, extorsión, secuestro, lavado de dinero, entre otros- recurrieran al uso de la fuerza, es decir, de las armas de fuego. De ahí la importancia de cuestionar ¿cuál ha sido el impacto de la fragilidad institucional en el control de armas de fuego en México y cómo se ha beneficiado la delincuencia organizada? En un primer momento, la falta de transparencia en el manejo de la información y los datos disponibles de 2013 muestran un país con gran disponibilidad de armas de fuego, véase Tabla 1.

Al considerar las estimaciones de 2005 y las cifras de 2013, cabe señalar que esta cantidad de armas que se muestran en la Tabla 1 están legalmente registradas y amparadas en el Artículo 10 de la Constitución Política de los Estados Unidos Mexicanos, en el que se señala que es una garantía constitucional para los residentes legales mexicanos y extranjeros- el acceso y posesión en su domicilio de una o varias armas de fuego, inclusive de diferente calibre, siempre y cuando no esté reservada para el uso exclusivo del ejército.

Artículo 10. Los habitantes de los Estados Unidos Mexicanos tienen derecho a poseer armas en su domicilio, para su seguridad y legítima defensa, con excepción de las prohibidas por la ley federal y de las reservadas para el uso exclusivo de la Fuerza Armada permanente y los cuerpos de reserva. La ley federal [...] determinará [...] los casos, condiciones, requisitos y lugares en que se pondrá a los habitantes la portación de armas. (Cámara de Diputados, 2021b)

2 En 2011, el exgobernador de Nuevo León, Sócrates Rizzo (1991-1996), declaró:

[...] la violencia del crimen organizado apareció en el país cuando desaparecieron los acuerdos de los gobiernos federales priistas con el narcotráfico en los que se establecían rutas de trasiego y se limitaban otros espacios. De alguna manera se tenía resuelto el conflicto del tránsito (de drogas); yo no sé cómo lo hayan resuelto otros gobiernos, pero había un control y había un estado fuerte y un presidente fuerte y una Procuraduría fuerte y había un control férreo del Ejército y entonces de alguna manera decían "tú pasas por aquí, tú por aquí, pero no me toques aquí estos lugares"; algo pasó (APRO, 2015). 
Tabla 1. Armas registradas para protección a domicilio por entidad federativa 2013

\begin{tabular}{|c|c|c|}
\hline Estado & Armas folios A* & Armas folio $\mathrm{F}^{* *}$ \\
\hline Aguascalientes & 11638 & 108 \\
\hline Baja California & 30402 & 578 \\
\hline Baja California Sur & 11901 & 195 \\
\hline Campeche & 27876 & 244 \\
\hline Chiapas & 32786 & 963 \\
\hline Chihuahua & 60475 & 1480 \\
\hline Coahuila & 31052 & 429 \\
\hline Colima & 25099 & 336 \\
\hline Ciudad de México & 134069 & 42220 \\
\hline Durango & 49474 & 333 \\
\hline Estado de México & 99309 & 24692 \\
\hline Guanajuato & 58131 & 875 \\
\hline Guerrero & 106234 & 2639 \\
\hline Hidalgo & 40802 & 1150 \\
\hline Jalisco & 98405 & 4888 \\
\hline Michoacán & 109163 & 1104 \\
\hline Morelos & 24724 & 1341 \\
\hline Nayarit & 27212 & 94 \\
\hline Nuevo León & 49270 & 2807 \\
\hline Oaxaca & 70646 & 1861 \\
\hline Puebla & 45204 & 2093 \\
\hline Querétaro & 21477 & 853 \\
\hline Quintana Roo & 18354 & 335 \\
\hline San Luis Potosí & 22694 & 430 \\
\hline Sinaloa & 69041 & 351 \\
\hline Sonora & 32469 & 262 \\
\hline Tabasco & 23850 & 538 \\
\hline Tamaulipas & 66645 & 345 \\
\hline Tlaxcala & 15617 & 454 \\
\hline Veracruz & 74411 & 2479 \\
\hline Yucatán & 44913 & 448 \\
\hline Zacatecas & 23674 & 248 \\
\hline Subtotal & 1557017 & 97173 \\
\hline Total & \multicolumn{2}{|c|}{1654190} \\
\hline
\end{tabular}

${ }^{*}$ Registro inicial de armas

** Registro de un arma nueva adquirida en la Dirección de Comercialización de Armas y Municiones (DCAM) de la Secretaría de la Defensa Nacional.

Fuente: Secretaría de la Defensa Nacional, solicitud de información, número 0000700026614, (Sedena, 2014b). 
En un segundo momento, y más allá de la gran cantidad de armas de fuego legales registradas en el país y de la fragilidad institucional para poder tener un control sobre ellas, se encuentra lo poco que se sabe sobre el tráfico ilegal de armas en el territorio nacional. Generalmente se habla de estimaciones sobre la cantidad de armas que entran al país, no obstante, sí se puede tener un primer escenario del impacto de este tipo de armas de fuego debido a que en el periodo 2013-2020 se contabilizaron 191784 homicidios dolosos de los cuales, en promedio, $65.86 \%$ han sido con armas de fuego - en 2020, 70\% de los homicidios dolosos en el país estuvo relacionado con armas de fuego- (Inegi, 2020; SESNSP, 2021).

\section{Armas, violencia homicida y la importancia de las instituciones}

Este escenario de violencia homicida va a la par de la fragilidad institucional que padece el Estado mexicano para poder contener el tráfico de armas en sus fronteras. Lo anterior se menciona debido a dos razones: 1) En la agenda sistémica, la discusión de la violencia homicida originada por armas ilegales en el país generalmente se centra de la relación bilateral con México y Estados Unidos. La narrativa gubernamental ha hecho pública su preocupación por las leyes estadounidenses que permiten la compra y venta de armas, muchas de las cuales terminan siendo traficadas y fortaleciendo a los grupos del crimen organizado en México (Caño, 2010; Ortega \& Mack, 2019). De esta manera se ha buscado responsabilizar únicamente a Estados Unidos de las consecuencias del tráfico de armas, pero sin detenerse en los vacíos normativos a nivel nacional que, a la postre, han contribuido a un incremento de la violencia homicida y al empoderamiento de la delincuencia organizada en México. 2) Lo anterior se refiere a los incentivos o a las lagunas normativas que se encuentran en las legislaciones en México que permiten rentabilizar, por la delincuencia organizada, las paradojas entre la LFafe y el Código Nacional de Procedimientos Penales (CNPP) en sus dos recientes reformas de 2016 y 2021 (véase Tabla 2).

Como política pública, la LFAFE es clara en el hecho de involucrar a los actores que intervienen en su implementación. Es importante recalcar el papel que juegan las fiscalías y ministerios públicos a nivel subnacional (Artículo 77). Es decir, generalmente es la Sedena quien asegura las armas y a las personas que las poseen y las presentan a las autoridades locales quienes a su vez deben comprobar, de acuerdo con las investigaciones, que son sujetos a los artículos $83 ; 83$ Bis y 84 . No obstante, en 2017, de acuerdo con Ángel (2017), 86\% de los consignados, más de 5 000, quedaron en libertad porque el CNPP en su Artículo 167 señalaba que la posesión de armas no ameritaba prisión preventiva y los fiscales — de acuerdo con el Artículo 321- en sus investigaciones no acreditaban la peligrosidad de los consignados. 
Tabla 2. Legislación para atender el tráfico de armas en México

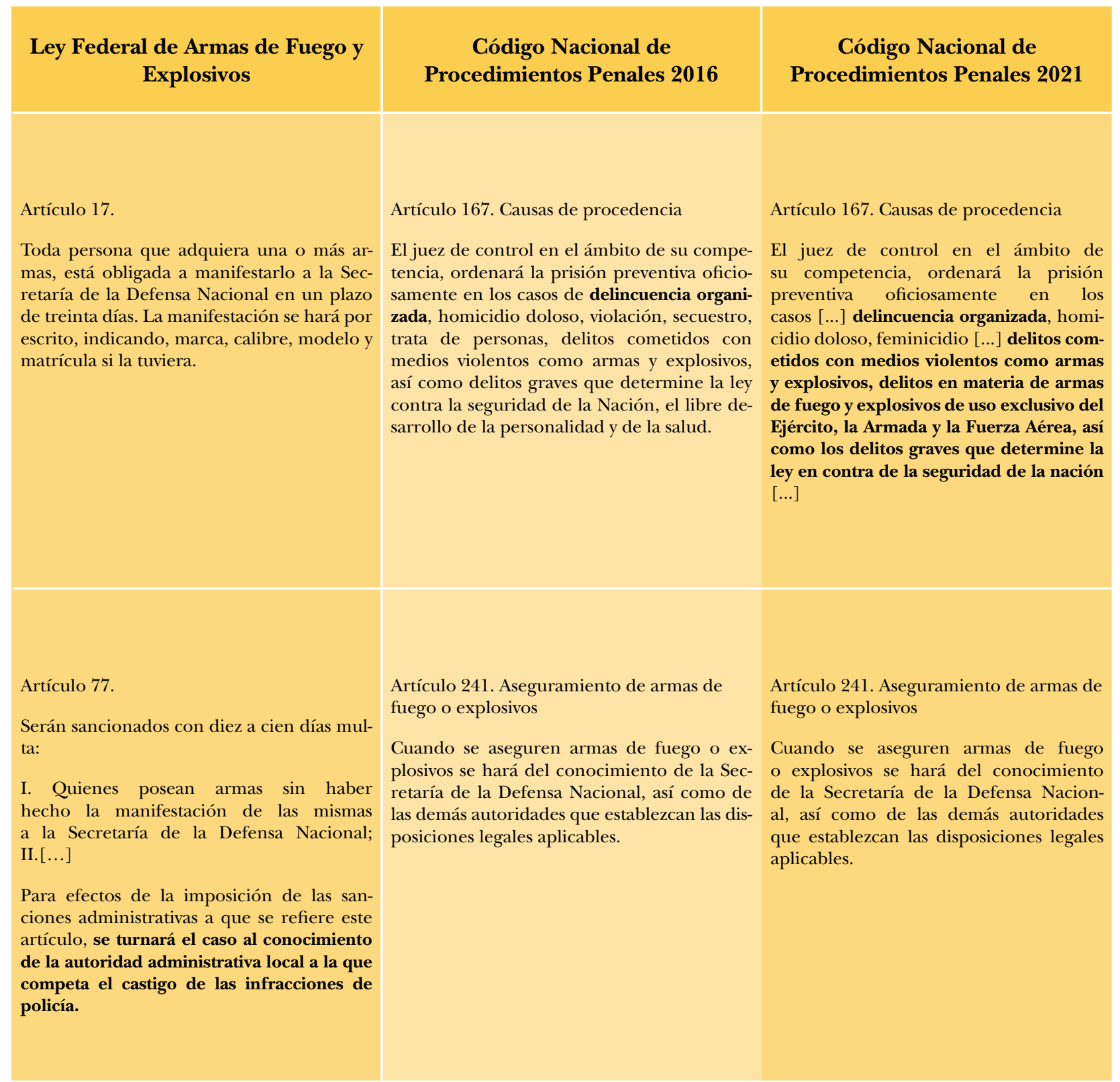


Artículo 83.

$\mathrm{Al}$ que sin el permiso correspondiente porte un arma de uso exclusivo del Ejército, Armada o Fuerza Aérea, se le sancionará:

I. Con prisión de tres meses a un año y de uno a diez días multa, cuando se trate de las armas comprendidas en el inciso i) del artículo 11 de esta Ley; II. Con prisión de tres a diez años y de cincuenta a doscientos días multa, cuando se trate de armas comprendidas en los incisos $a$ ) y $b$ ) del artículo 11 de esta Ley, y III. Con prisión de cuatro a quince años y de cien a quinientos días multa, cuando se trate de cualquiera de las otras armas comprendidas en el artículo 11 de esta Ley.

En caso de que se porten dos o más armas, la pena correspondiente se aumentará hasta en dos terceras partes.

Cuando tres o más personas, integrantes de un grupo, porten armas de las comprendidas en la fracción III del presente artículo, la pena correspondiente a cada una de ellas se aumentará al doble.

Artículo 83 Bis.

$\mathrm{Al}$ que sin el permiso correspondiente hiciere acopio de armas, se le sancionará:

I. Con prisión de dos a nueve años y de diez a trescientos días multa, si las armas están comprendidas en los incisos $a$ ) o $b$ ) del artículo 11, de esta Ley. En el caso del inciso $i$ ) del mismo artículo, se impondrá de uno a tres años de prisión y de cinco a quince días multa; y II. Con prisión de cinco a treinta años y de cien a quinientos días multa, si se trata de cualquiera otra de las armas comprendidas en el artículo 11 de esta Ley.

Por acopio debe entenderse la posesión de más de cinco armas de las de uso exclusivo del Ejército, Armada y Fuerza Aérea.

Para la aplicación de la sanción por delitos de portación o acopio de armas, el Juez deberá tomar en cuenta la actividad a que se dedica el autor, sus antecedentes y las circunstancias en que fue detenido.
Artículo 321. Plazo para la investigación complementaria

El Ministerio Público deberá concluir la investigación complementaria dentro del plazo señalado por el Juez de control, mismo que no podrá ser mayor a dos meses si se tratare de delitos cuya pena máxima no exceda los dos años de prisión, ni de seis meses si la pena máxima excediera ese tiempo o podrá agotar dicha investigación antes de su vencimiento.
Artículo 321. Plazo para la investigación complementaria

El Ministerio Público deberá concluir la investigación complementaria dentro del plazo señalado por el Juez de control, mismo que no podrá ser mayor a dos meses si se tratare de delitos cuya pena máxima no exceda los dos años de prisión, ni de seis meses si la pena máxima excediera ese tiempo o podrá agotar dicha investigación antes de su vencimiento.
Artículo 327. Sobreseimiento

El Ministerio Público, el imputado o su Defensor podrán solicitar al Órgano jurisdiccional el sobreseimiento de una causa [...]

El sobreseimiento procederá cuando:

V. Agotada la investigación, el Ministerio Público estime que no cuenta con los elementos suficientes para fundar una acusación;
Artículo 327. Sobreseimiento

El Ministerio Público, el imputado o su Defensor podrán solicitar al Organo jurisdiccional el sobreseimiento de una causa [...]

El sobreseimiento procederá cuando:

V. Agotada la investigación, el Ministerio Público estime que no cuenta con los elementos suficientes para fundar una acusación; 


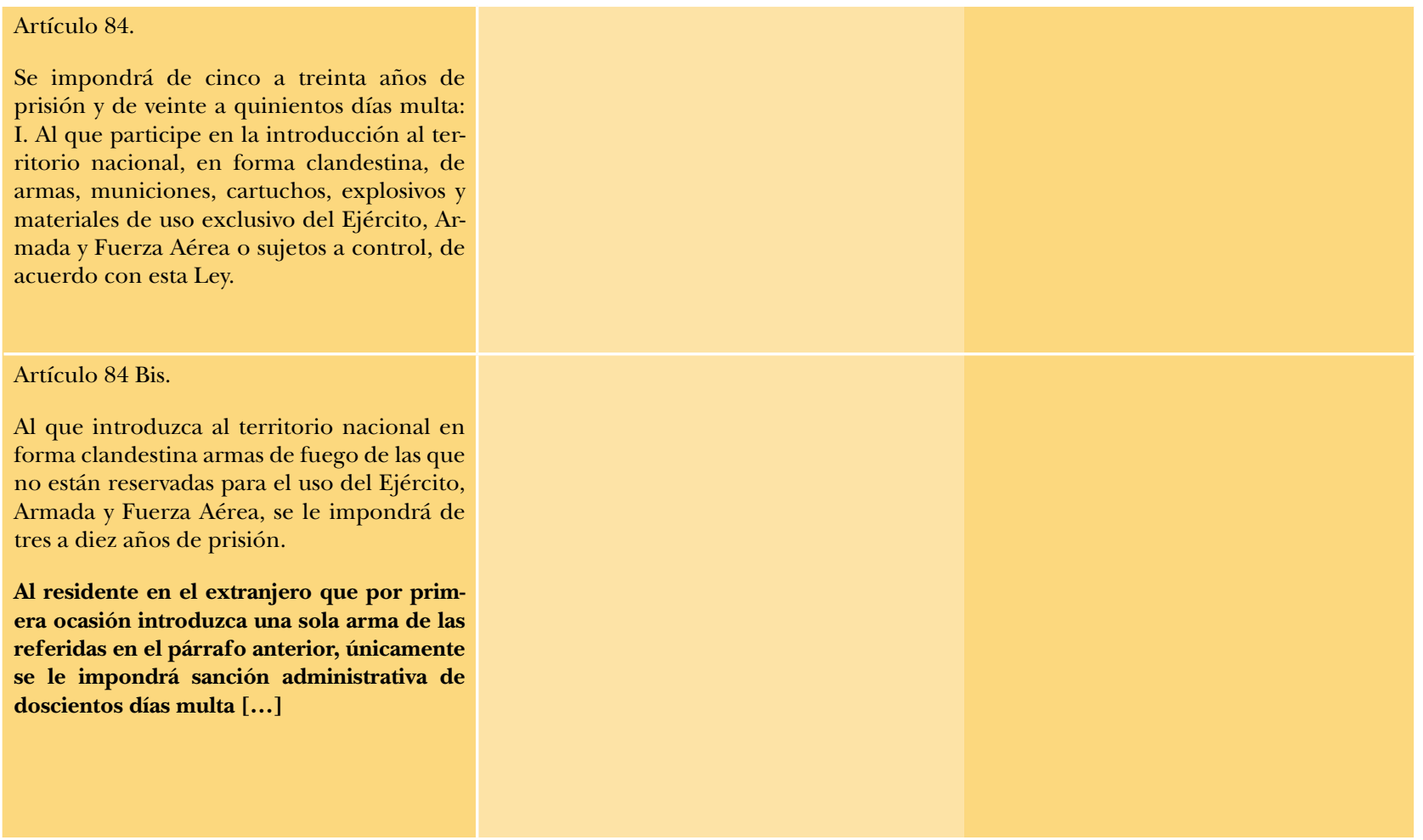

Fuente: Elaboración propia con información de la Ley Federal de Armas y Explosivos (2021) y el Código Nacional de Procedimientos Penales (2016 y 2021, Cámara de Diputados, 2021a, 2021c)

Lo anterior se debió en parte a la entrada en vigor del Nuevo Sistema de Justicia Penal —en el que se aprobó la miscelánea del cNPP— en 2016 de corte oral y adversarial, mismo que, debido la falta de recursos económicos y humanos, así como a la falta de capacitación de algunos operadores del sistema de seguridad y justicia, presentó el fenómeno de "puerta giratoria" ${ }^{3}$ para los presuntos culpables por portación de armas de fuego (México Evalúa, 2019; Ingram et al., 2011, pp. 4-135; Semple, 2020). En 2021, se realizó una reforma al CNPP para modificar, entre otros, el Artículo 167 y así incluir la prisión preventiva en materia de tráfico y posesión de armas de uso exclusivo del Ejército. Aun así, la Fiscalía y ministerios públicos son quienes deberán realizar sus averiguaciones, como un segundo proceso, para comprobar al presunto culpable como integrante de la delincuencia organizada, a manera de complementar la investigación judicial y formar el caso.

En este mismo sentido, el problema del control del Estado sobre las armas no solo se centra en los individuos que poseen armas de uso exclusivo del Ejército, sino también en los ciudadanos que poseen armas de acuerdo con el Artículo 17 de la LFAFE. En dicho artículo se estipula la obligación de reportar, en un plazo de treinta días, a la Sedena la

${ }^{3}$ El término "puerta giratoria" se refiere a la libertad que obtienen las personas detenidas por delitos establecidos en el Código Penal, ya que las lagunas de la legislación permiten que los imputados puedan evadir el castigo correspondiente. 
posesión de un arma; de no hacerlo el artículo 77 señala sanciones de diez a cien días de multa. Lo paradójico de la sanción se encuentra en que, teniendo un incremento en la tasa de delitos cometidos por armas de fuego en el país, estos dos artículos hayan sido reformados en 1985 y 1998 respectivamente. De acuerdo con el Instituto Belisario Domínguez, este tipo de lagunas normativas ha permitido que en el país existan 1.7 millones de armas ilegales en posesión de particulares (Aguirre Quezada, 2020, p. 3). De ahí que se hayan dado sucesos como los ocurridos en Torreón, Coahuila, donde, en enero de 2020, un menor de edad asesinó a profesores y compañeros con armas de uso exclusivo del Ejército, las cuales eran propiedad del abuelo y no tenían permiso de portación (Salinas Maldonado, 2020).

Otro de los puntos importantes a considerar al analizar la LFAFE se encuentra en el Artículo 84 Bis —reformado en 1998- que plantean únicamente sanciones administrativas y multas para los ciudadanos extranjeros que introduzcan por primera vez armas al país. Esto ayudaría a explicar la rentabilidad que la delincuencia organizada encuentra en incentivar el denominado tráfico hormiga de armas. En 2019, la Sedena estimó que mediante este modus operandi ingresaron al país 200000 armas al año, un promedio de 567 armas al día y $70 \%$ de ellas entran por la frontera norte (Nájar, 2019). La información disponible plantea que $95 \%$ de las personas que ingresan con armas cortas $-80 \%$ de las incautaciones se relacionan a este tipo de revólveres-, largas o cartuchos al país son ciudadanos estadounidenses; estas personas reciben de los grupos de la delincuencia organizada desde 100 a 2000 dólares por paquetes de balas o rifles automáticos (González, 2021; Medina, 2020, p. 185; unODC, 2020, p.10). Estas lagunas normativas expuestas necesariamente conducen a explicar y analizar el impacto de la regulación de armas en el país.

\section{Baja California, consecuencias regionales de las armas sin fronteras}

Una de las primeras consecuencias a nivel nacional de la falta del control de armas en México está en el hecho de que, en 2020, 70\% de los homicidios dolosos en el país estuvo relacionado con armas de fuego. Este panorama evidencia que, a pesar de que la agenda sistémica mantiene en la discusión temas como la inseguridad, la violencia homicida y la presencia de armas de fuego en el país, el Estado mexicano ha mostrado fragilidad en la implementación en la política de armas. Se hace referencia a esto porque la incautación de armas en el país no ha tenido respuestas excepcionales y, en contraparte, los homicidios dolosos por armas de fuego han aumentado (véase Figura 1). 
Figura 1. Homicidios dolosos por armas de fuego y decomiso de armas a nivel nacional 2013-2020

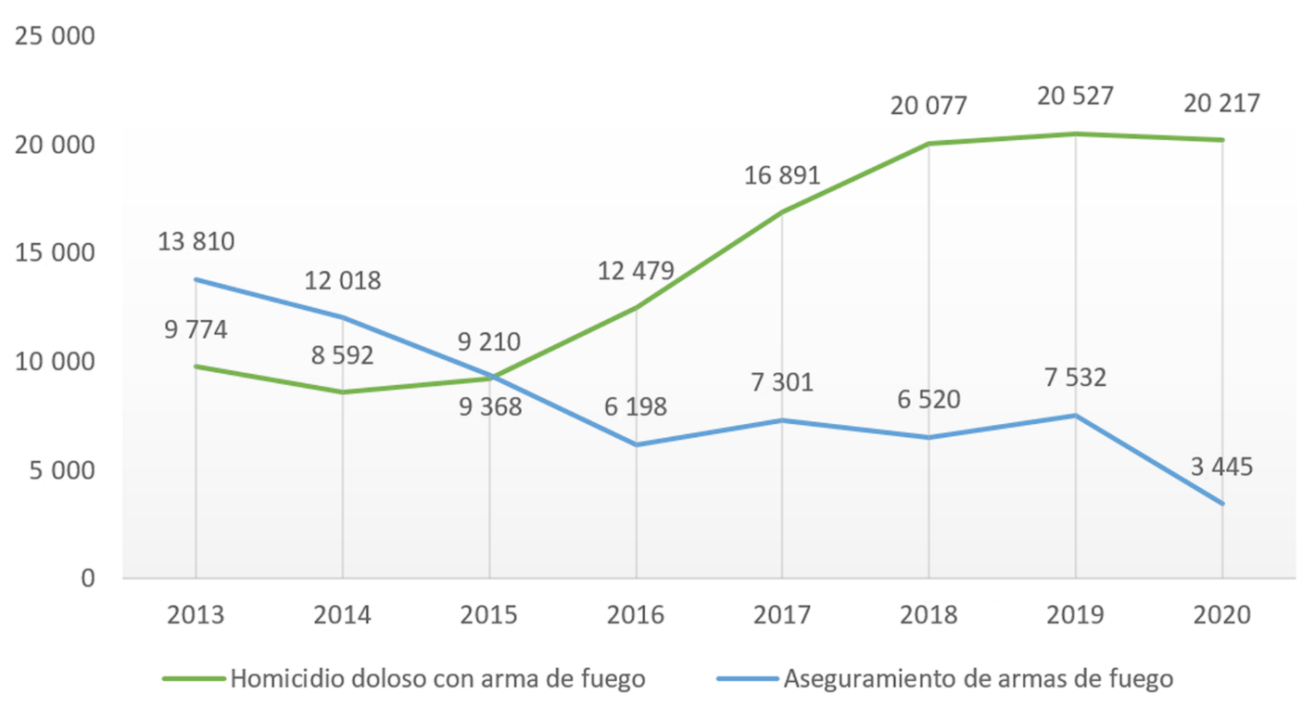

Fuente: Elaboración propia con datos del Secretariado Ejecutivo del Sistema Nacional de Seguridad Pública 2013-2020; y el 2 Informe de Gobierno (2019-2020) del presidente Andrés Manuel López Obrador (Presidencia de la República, 2020).

Aunado a la caída de incautación de armas de fuego en México está el hecho de las armas ilegales que han ingresado al país. En el periodo 2009-2019, la Sedena estimó la entrada de manera ilegal de 2012573 de armas (Aguirre Quezada, 2020, p. 3). Esta gran cantidad de armas necesariamente ha impactado en la consolidación de otro de los agentes no gubernamentales que se involucran en la política del control de armas en el país, es decir, la delincuencia organizada. Este panorama nacional también tiene impactos a nivel regional como la zona noroeste, específicamente Baja California, que de acuerdo con el Índice de Paz México 2020, es la entidad que consecutivamente en 2019 y 2020 ha sido la menos pacífica del país (IEP, 2020, p. 4). Lo anterior, tiene sentido si se considera que la violencia homicida en el estado está relacionada con el tráfico de armas y con las disputas entre grupos de la delincuencia organizada, lo cual ha generado espirales de violencia desde las administraciones estatales 2013-2019 y la 2019-2021 (véase Figura 2).

La Figura 2 no solo muestra el impacto de las armas en Baja California, sino también lo estratégico que resulta para la delincuencia organizada este territorio fronterizo, el cual posee la frontera más dinámica del país. ${ }^{4}$ Cabe señalar que, de acuerdo con la Oficina de la Secretaría de Relaciones Exteriores (SRE), Baja California — detrás de Tamaulipas y Sonora- es la entidad por donde ingresa el mayor número de armas largas al país, y de manera específica, los principales cruces de mayor dinamismo son: Tijuana, Ensenada y La Rumorosa (Medina, 2020, pp. 184-185). En el caso de Mexicali, la capital de Baja California, la violencia incrementada, sobre todo en el

${ }^{4}$ Por ejemplo, en 2019, el cruce peatonal en San Isidro fue de 7300000 personas y 25550000 automóviles (Notimex, 2019). 
valle de Mexicali, durante 2020 y 2021, ha generado que la aduana de Mexicali se haya convertido en un punto estratégico para el trasiego de armas (López Ponce, 2020). Como se plantea en los referentes teóricos, la implementación de una política pública involucra una serie de actores, y en los cruces fronterizos las aduanas son fundamentales para la instrumentación de la LFAFE. No obstante, en abril de 2021 se dio a conocer que la Unidad de Inteligencia Financiera denunció penalmente a los administradores de las aduanas de Tijuana, Mexicali y Tecate por corrupción al permitir el ingreso ilegal de mercancías, combustible, drogas y armas a México (Álvarez, 2021).

Figura 2. Decomiso de armas de fuego y homicidios dolosos en Baja California (2013-2020)

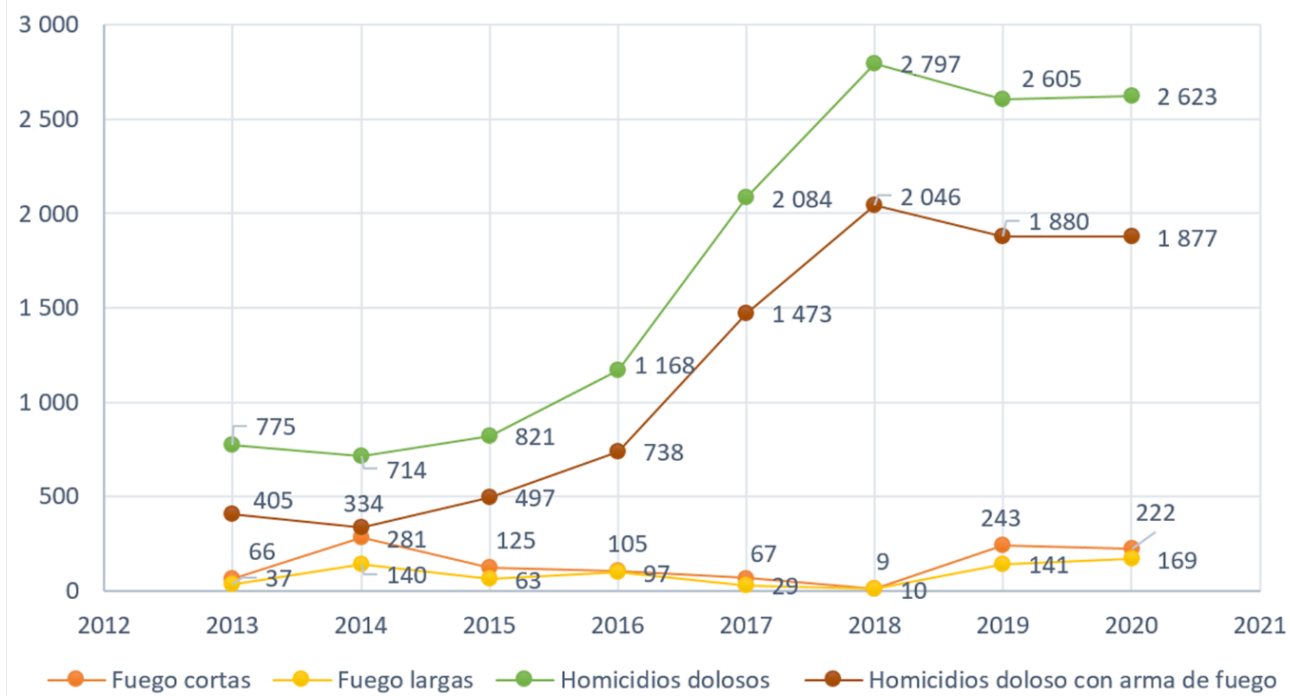

Fuente: Elaboración propia con datos del Primer Informe de Gobierno de Francisco Arturo Vega de Lamadrid (Comité de Planeación para el Desarrollo del Estado [Coplade], 2014); 2 Informe de Gobierno (2019-2020) del presidente Andrés Manuel López Obrador (Presidencia de la República, 2020); Anuario estadístico y geográfico por entidad federativa (Inegi, 2019); y datos de incidencia delictiva por estado, de fuero común, sistematizados por el SESNSP.

Bajo esta tesitura, y ante la evidente falla en la instrumentación de la política pública, el análisis del tráfico de armas de fuego en México y sus impactos regionales como el caso de Baja California necesariamente tiene que hacer hincapié en lo que han realizado los gobiernos de Estados Unidos y México para atender el fenómeno. Máxime cuando la narrativa presente en la agenda sistémica pareciera inclinarse a responsabilizar a las leyes estadounidenses y a las armerías por su facilidad al acceso de armas. Esto se menciona porque en México, desde hace dos décadas y cuatro administraciones federales (2000-2006; 2006-2012; 2012-2018 y la actual 2018-2024) se ha externado la preocupación ante Estados Unidos por el tráfico ilegal de armas estadounidenses a territorio nacional que ha fortalecido a la delincuencia organizada (Ortega \& Mack, 2019).

Lo anterior ha dado como resultado el trabajo binacional para atender diferentes temas de fronteras donde no necesariamente el tráfico de armas ha sido el factor más determinante en la relación entre países: 
- En 2005 se firmó el operativo de Fronteras Seguras, el cual tenía un enfoque de control migratorio debido a que organizó a cuatro entidades que operaban la seguridad fronteriza: Aduanas y Protección Fronteriza; el Servicio de Inmigración y Control de Aduanas; los Servicios de Inmigración y Ciudadanía; y la Guardia Costera (Cámara de Comercio México-Estados Unidos, 2011, p. 5).

- En 2008, Estados Unidos y México firmaron la Carta de Acuerdo de la Iniciativa Mérida, la cual tuvo como finalidad reconocer las responsabilidades compartidas de Estados Unidos y México para contrarrestar la violencia alimentada por las drogas que amenazaba a los ciudadanos de ambos lados de la frontera (Ocampomi, 2021).

- En 2009, la Iniciativa Mérida involucró operativos binacionales como el denominado "Rápido y Furioso" (Fast and Furious) en el cual se introdujeron armas, como señuelos, a México para ser rastreadas e identificar las rutas del tráfico de armas, situación que fracasó con la pérdida de 2500 armas (u.s. Department of Justice, 2012).

- En 2019, se llevó a cabo el operativo "Frozen" que se diseñó para frenar el tráfico de armas a través de la incautación en puntos de inspección en cruces fronterizos como San Diego-Tijuana, El Paso-Ciudad Juárez, LaredoNuevo Laredo, McAllen-Reynosa y Brownsville-Matamoros (Sánchez, 2019).

Ante esto es importante mencionar que el gobierno de Estados Unidos ha apostado por otros intereses - por ejemplo, la lucha contra el terrorismo- y el tema del tráfico de armas de fuego lo ha reducido a operativos. Esto, desde la perspectiva teórica, se podría explicar debido a la fortaleza de sus estructuras institucionales, es decir, que la violencia homicida por armas de fuego y relacionada con la delincuencia organizada no representa un cuestionamiento al control territorial en sus ciudades fronterizas con Baja California. De manera específica, en el periodo 2013-2020 en los distritos 50 (Alpine, Escondido, Ramona, Borrego Desert), 51 (San Ysidro, Imperial Beach, Brawley, El Centro, Salton City), 52 (San Diego, Miramar, La Jolla, Poway, Coronado, Point Loma) y 53 (Bonita, El Cajon, Chula Vista, La Mesa, Lemon Grove, Spring Valley), la violencia homicida relacionada con las armas de fuego ha sido mucho menor en comparación con la que se presenta en ciudades como Tijuana, Mexicali, Tecate, Rosarito y Ensenada (véase Figura 3).

De esta manera, aun cuando la responsabilidad de Estados Unidos y su legislación para la venta de armas tiene un peso determinante, los gobiernos mexicanos no han asumido el compromiso en torno a su propia legislación. En este punto es importante destacar que la respuesta del gobierno subnacional en las dos administraciones Francisco Vega de Lamadrid (2013-2019) y Jaime Bonilla Valdez (2019-2021) - que abarca el estudio ha sido la de adherirse a la Campaña de canje de armas y desarme voluntario implementada por la Sedena y estipulada en el Artículo 5 de la LFAFE (Redacción/El Vigia, 2019; Editorial Staff, 2019). Es decir, el impacto de las armas de fuego circulando ilegalmente en la entidad ha sido minimizado por los actores involucrados en la implementación de la LFAFE. 
Figura 3. Homicidios dolosos relacionados con armas de fuego en ciudades fronterizas de California, Estados Unidos, y Baja California, México, 2013-2020

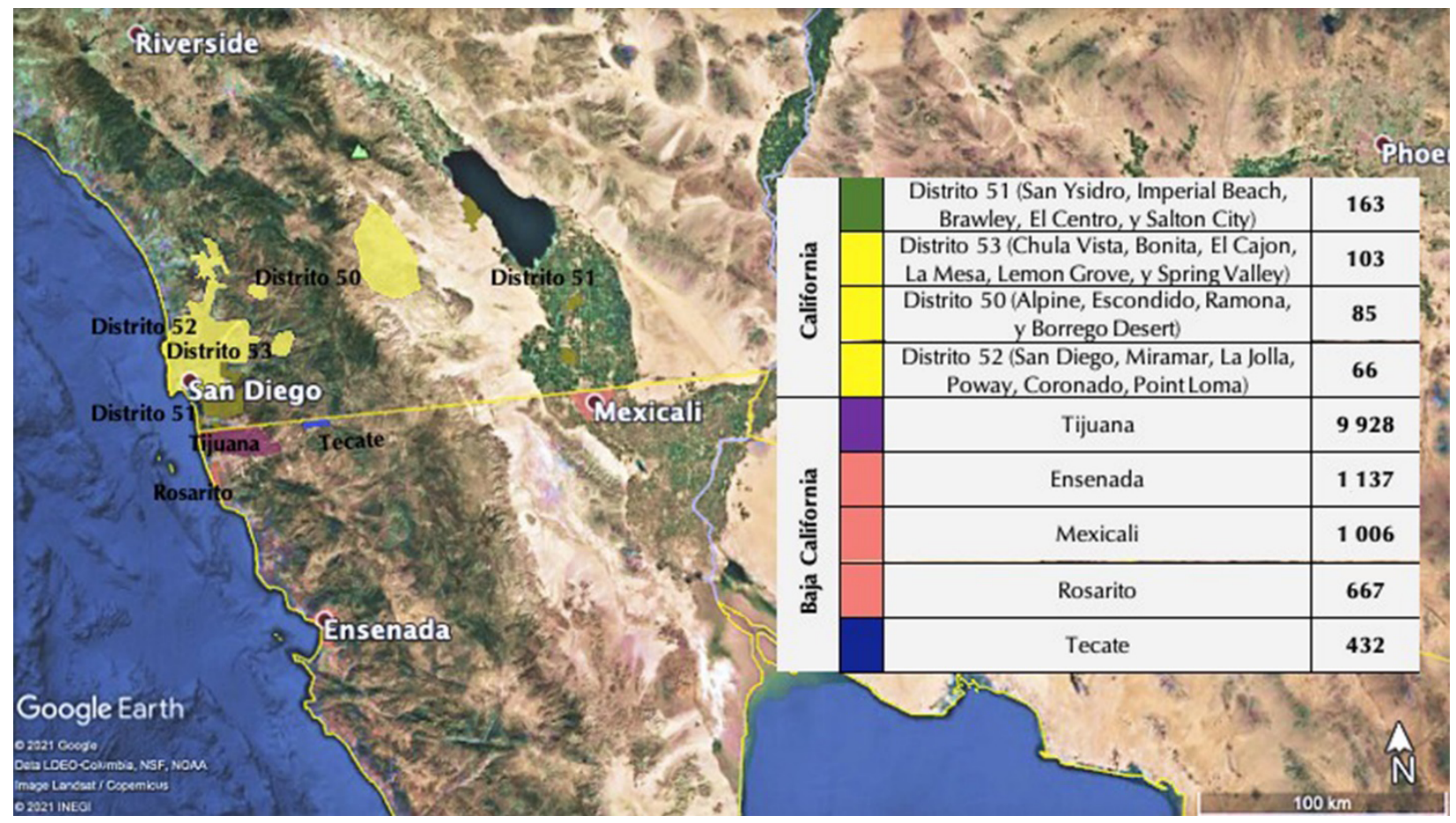

Fuente: Elaboración propia con datos de incidencia delictiva estatal y municipal sistematizados por la Guardia Estatal de Seguridad e Investigación (GESI, 2021) y el Gun Violence Archive CA Stats de la organización civil Gun Violence Archive (GVA, 2021)

De esta manera, el efecto del trasiego de armas en un territorio como el de Baja California no solo se puede observar por los homicidios dolosos sino también por la percepción de inseguridad que se vive en la entidad. En los dos periodos de gobierno estatal que se estudian - y con la información disponible en la Encuesta Nacional de Seguridad Pública Urbana (Inegi, 2021b) —, entre 2016 y 2020, Tijuana y Mexicali, las dos principales ciudades fronterizas de Baja California, han tenido en promedio una percepción de inseguridad de $71.92 \%$ y $68.2 \%$, respectivamente. Asimismo, Ensenada en 2018 tuvo una tasa de 46.6 homicidios por cada 100000 habitantes, en 2020 esta tasa llegó a 90.58, lo que la ubicó, junto con Tijuana, entre las primeras seis de las 50 ciudades más violentas del mundo (Seguridad Justicia y Paz, 2021).

Este panorama evidencia que, al no poder contener la inseguridad y la violencia generada por las armas de fuego, las repercusiones a corto, mediano y largo plazo han sido sobre la sociedad debido a que la percepción de inseguridad también se presenta en el retiro comunitario y la fragmentación del tejido social. Esto se observa en la poca confianza que se tiene en la efectividad del gobierno en dos de las ciudades estratégicas para el cruce de armas: Tijuana con 12.08\% y en Mexicali con 21.98\% (Inegi, 2021b). A la postre, un fenómeno como el tráfico de armas de fuego revela que un problema no atendido no hace más que crecer, lo que deriva en otras problemáticas que complejizan aún más la capacidad de respuesta de los gobiernos federal, estatal y locales. 
Así, el tráfico de armas de fuego y su poco control evidencian los retos que tiene el Estado mexicano para contrarrestar las implicaciones de violencia homicida que se viven en regiones como Baja California. No obstante, para entender los desafíos a los que se debe hacer frente es importante no dejar de lado los planteamientos teóricos que señalan que la delincuencia organizada — como máximo beneficiado por el trasiego de armas de fuego- es un agente criminal con una marcada dimensión trasnacional. Esto, por ejemplo, significa que la delincuencia organizada trafica armas de fuego desde América del Norte hacia las otras subregiones como América del Sur y América Central (UnODC, 2020, p. 9).

Esta capacidad de adaptación de la delincuencia organizada para traficar armas de fuego de una región a otra ha generado que las agendas nacionales se vean rebasadas por un fenómeno mundial en el cual - como en el caso de México- la fragilidad institucional de los Estados nación tiene un rol determinante en el éxito de la implementación de políticas de control de armas. Asimismo, la característica que comparten estas subregiones ha sido la violencia homicida, la percepción de inseguridad, frágil estado de derecho, expulsión de personas de sus lugares de origen por la falta de seguridad y empleo, entre otras. Pese a todo, hay áreas de oportunidad que Estados como el mexicano puede abordar para robustecer su andamiaje ante problemas que han crecido y que no solo amenazan, sino que asolan a regiones como Baja California. De esta manera, ante los desafíos del tráfico de armas de fuego se propone:

- Ante el incremento del tráfico hormiga de armas de fuego por ciudadanos extranjeros o de doble nacionalidad, el marco regulatorio en México debería reformar el Artículo 84 Bis para elevar los costos de aquellas personas que decidan incurrir en el delito de tráfico de armas de fuego o partes de estas.

- Ante el poco control que existe sobre el registro de las armas de fuego ilegales en todo el país, y sobre todo a nivel subnacional, sería pertinente que el Estado mexicano en coordinación, por ejemplo, con la onu y la Organización de Estados Americanos (OEA) cree un órgano auditor externo para establecer mecanismos que ayuden a los gobiernos subnacionales al rastreo y registro de armas de fuego ilegal en sus territorios.

- Si bien en esta investigación no se hizo hincapié, por falta de información, en las armas de fabricación casera o hechizas, las fuentes periodísticas reportan cada vez más sobre este tipo de armas de fuego, por tal motivo el marco regulatorio en México debería actualizar y prever la contención de este fenómeno ante la ola de violencia y facilidad de fabricación en laboratorios clandestinos.

- Es necesario reformar los preceptos - del Artículo 10 que tiene que ver con el derecho a poseer armas, del Artículo 17 que obliga al registro de las mismas en un periodo de 30 días y las sanciones que se encuentran en el Artículo 77- para dificultar la posesión de armas por los ciudadanos, e incrementar los costos por no cumplir con los registros de las armas de fuego.

$\mathrm{Si}$ bien estas propuestas que se plantean al marco regulatorio no necesariamente implican que la política de armas de fuego en México vaya a solucionar el tráfico de las mismas, sí redirige y posiciona su relevancia en la agenda sistémica e institucional. Asimismo, es pertinente considerar que gran parte de la responsabilidad se encuentra en la LFAFE y en las lagunas legales que han permitido que la delincuencia organizada 
rentabilice y consolide - a través de lo que significa el acceso a las armas de fuego- sus estructuras criminales. Por tal motivo, sin un andamiaje sólido y robusto difícilmente los operativos de la Sedena, Aduanas y los gobiernos estatales y locales tendrán un impacto permanente en la incautación de armas de fuego. Al tener una estructura institucional robusta, un gobierno subnacional como Baja California podría tener mejores recursos para hacer frente al trasiego de armas, sobre todo, al tomar en consideración lo que sucede en el estado vecino de California y su lucha para contener el libre acceso a las armas de fuego por sus ciudadanos. En otras palabras, tras centenares de tiroteos en Estados Unidos como consecuencia de una legislación proarmamentista, donde múltiples víctimas perdieron la vida en la década de 1980, California, en términos generales, realiza un esfuerzo por mantenerse como estado a favor del control de las armas de fuego (McGreevy, 2021). Lo anterior resulta una hazaña de las autoridades estatales debido a la normatividad que garantiza el derecho civil a la posesión de armas, a través de la Segunda Enmienda (Declaración de Derechos, 1689) y leyes federales (por ejemplo, National Firearms Act, Gun Control Act of 1968, Protection of Lawful Commerce in Arms Act, entre otras).

Si bien es cierto que lo anterior pareciera mostrar que hay un doble discurso pues, por un lado, se limita a fortalecer la narrativa de posesión de armas de fuego, pero, por el otro, mantiene el consumo masivo de armas a través de ferias y el pago módico de impuestos. De hecho, en 2021, el Poder Judicial Federal ${ }^{5}$ autorizó la portación de armas largas en el estado (France24, 2021). Aun con esto, hay varias demandas relacionadas con el acceso a municiones para este tipo de armamento, paralelo a la iniciativa de ley denominada SB-264 que pretende prohibir la entrada a promotores de ferias de armas de fuego a espacios públicos que están bajo la autoridad del condado (California Legislative Information, 2021).

\section{Conclusiones}

En el documento se analizó el tráfico de armas de fuego de Estados Unidos hacia México y la correlación con la violencia homicida en la región noroeste del país, específicamente Baja California. Se observó que, entre menos decomisos de armas de fuego en Baja California, mayor la violencia criminal asociada a estas. Para comprobar la hipótesis planteada en el estudio se analizó la política de armas en el país, específicamente la Ley Federal de Armas de Fuego y Explosivos (LFAFE) y el Código Nacional de Procedimientos Penales (CNPP), para identificar las lagunas legales de las cuales se han servido los grupos delictivos y todos aquellos individuos dedicados a traficar armas en el país.

Asimismo, se expuso el histórico desinterés de la incautación de armas de fuego en el país. Esto, de acuerdo con los referentes teóricos y de la agenda institucional, podría deberse a la falta de capacidad institucional para hacer frente al hecho delictivo, así como intereses disolutos por aquellas autoridades responsables de la incautación de armas de fuego. Un ejemplo de esto son los gobiernos subnacionales o las aduanas, y la opacidad para implementar in situ la política pública en el marco de la LFAFE y el CNPP. Como resultado de lo anterior, se carece de datos actualizados y fehacientes de armas de fuego, mientras que también se tiene una sociedad profundamente armada e

${ }^{5}$ Juez federal Roger Benítez del Tribunal del Distrito de San Diego, California. 
insegura. Este delito comienza a estudiarse con detalle en distintas latitudes mexicanas debido a que resulta clave para el desarme y la pacificación del país.

Es importante dejar claro que no basta la preocupación de las administraciones federales ante el problema de las armas ilícitas, de ahí que se aplauda a la postura del Gobierno Federal 2018-2024, a través de la Secretaría de Relaciones Exteriores, por la presentación de la demanda contra fabricantes y vendedoras de armas — Smith \& Wesson Brands Inc., Barrett Firearms Manufacturing Inc., Beretta Holdings Spa., Beretta U.S.A. Corp., Century International Arms Inc., Colt's Manufacturing Company LLC., Glock Ges. M.B.H., Glock Inc., Sturm, Ruger \& Co. Inc., Witmer Public Safety Group Inc., Interstate Arms-que busca la reparación del daño por lo laxo de la regulación estadounidense en materia de armas de fuego. El futuro de la demanda es incierto, sin embargo, marca un hito para la agenda pública y la lucha contra la inseguridad relacionada con la actividad de la delincuencia organizada. Asimismo, es un paso en la búsqueda de soluciones que sean integrales, es decir, para que se revise la legislación en materia de armas en Estados Unidos, así como la legislación de la LFAFE en México. Idealmente, las autoridades deben poner los puntos sobre las íes para ser precisas y eficientes en su labor cotidiana, de acuerdo con la agenda institucional. Ante un problema como el abordado se requiere del acompañamiento técnico de organismos internacionales, la academia mexicana y organismos especializados de la sociedad civil.

\section{Referencias}

Adame, W. (2021, 1 de marzo). Deberá Sedena investigar cartuchos faltantes en policía de Silao. Milenio. https://www.milenio.com/policia/debera-sedena-investigar-cartuchos-faltantes-policia-silao

Aguirre Quezada, J. P. (2020). Armas de fuego en la sociedad mexicana. Riesgos para la paz y la seguridad pública. Mirada legislativa, (193). http://bibliodigitalibd. senado.gob.mx/handle/123456789/5034

Álvarez, C. (2021, 15 de abril). uif denuncia corrupción en aduanas de Tijuana, Mexicali y Tecate; empresas "fantasma", sobornos y nexos con narco. Zeta. https://zetatijuana.com/2021/04/uif-denuncia-corrupcion-en-aduanas-de-tijuana-mexicali-ytecate-empresas-fantasma-sobornos-y-nexos-con-narco/

Andreas, P. (2004). Illicit international political economy: the clandestine side of globalization. Review of International Political Economy, 11(3), 641-652.

Andrews, K. \& Caren, N. (2010). Making the news: movement organizations, media attention, and the public agenda. American Sociological Review, 75(6), 841-866. https://doi.org/10.1177\%2F0003122410386689

Ángel, A. (2017, 29 de junio). Más de 5 mil consignados por portar armas de alto poder están libres con el nuevo sistema. Animal Político. https://www.animalpolitico. com/2017/06/consigandos-armas-estan-libres/

APRO. (2015, 9 de noviembre). Controlaban presidentes priistas al narco: Rizzo. Noroeste. https://www.noroeste.com.mx/nacional/controlaban-presidentes-priistas-al-narco-rizzo-MANO322691

Astorga, L. (2015). Drogas sin fronteras. Debolsillo. 
Beltrán, U. \& Cinta, A. (1998). Medios de comunicación y agenda pública. En F. Serrano Migallón (Coord.), Homenaje a Rafael Segovia (pp. 295-327). El Colegio de MéxiCo/FCE/Conacyt. https://muse.jhu.edu/chapter/2587015

Buzan, B. (1988). People, states and fear: the national security problem in the Third World. En E. E. Azar \& C-I Moon (Eds.), National security in the Third World: the management of internal and external threats (pp. 15-35). University of Maryland Center.

California Legislative Information. (2021). SB-264 Firearms: the OC Fair and Event Center. https://leginfo.legislature.ca.gov/faces/billTextClient.xhtml?bill_ id $=202120220$ SB264

Cámara de Comercio México-Estados Unidos. (2011). Documento temático 1 -EE.UU.-México Cooperación en Seguridad. https://usmcoc.org/papers-current/1-EE\%20UU-Mexico-Cooperacion-en-Seguridad.pdf

Cámara de Diputados. (2006). Informes presidenciales. Luis Echeverría Álvarez. http:// www.diputados.gob.mx/sedia/sia/re/RE-ISS-09-06-14.pdf

Cámara de Diputados. (2021a). Código Nacional de Procedimientos Penales (Última reforma publicada en el DOF, 19-02-2021). http://www.diputados.gob.mx/LeyesBiblio/pdf/CNPP_190221.pdf

Cámara de Diputados. (2021b). Constitución Política de los Estados Unidos Mexicanos (Última reforma en materia de seguridad privada, publicada en el Diario Oficial de la Federación el 28 de mayo de 2021). http://www.diputados.gob.mx/LeyesBiblio/ref/cpeum.htm

Cámara de Diputados. (2021c). Ley Federal de Armas de Fuego y Explosivos. http://www. diputados.gob.mx/LeyesBiblio/pdf/102_190221.pdf

Caño, A. (2010, 20 de mayo). Calderón denuncia ante el Congreso la responsabilidad de EEUU en el narcotráfico. El País. https://elpais.com/internacional/2010/05/20/actualidad/1274306417_850215.html

Casar, M. A. \& Maldonado, C. (2010). Formación de agenda y proceso de toma de decisiones. Una aproximación desde la ciencia política. En M. Merino \& G. Cejudo (Comps.), Problemas, decisiones y soluciones. Enfoques de política pública (pp. 220-235). FCE/CIDE.

Centro de Estudios Sociales y de Opinión Pública (CESOP). (2016). Seguridad y participación ciudadana. Encuesta territorial nacional. Cámara de Diputados. http:// www5.diputados.gob.mx/index.php/esl/content/download/65407/329550/ file/CESOP-IL-14-ETERSeguridadyParticipacionCiudadana-161206.pdf

Cobb, R. \& Elder, C. (1972). Participation in American politics: The dynamics of agenda-building. The Johns Hopkins University Press.

Cobb, R., Ross, J-K. \& Ross, M. H. (1976). Agenda buildig as a comparative political process. The American Political Science Review, 70(1), 126-138. https://doi. org/10.2307/1960328

Comité de Planeación para el Desarrollo del Estado (Coplade). (2014). Primer informe de gobierno Francisco Arturo Vega de Lamadrid. https:/ / www.yumpu.com/es/docu$\mathrm{ment} / \mathrm{read} / 27251211 /$ primer-informe-de-gobierno-de-kiko-vega

Coss Nogueda, M. (2005). Armas pequeñas y ligeras: Caso México. Oxfam. https://www. casede.org/index.php/biblioteca-casede-2-0/armas/181-armas-pequenas-y-ligeras-caso-mexico/file 
Déziga, P. (2020, 12 de febrero). Tráfico de armas: una historia de éxito. Animal Político. https://www.animalpolitico.com/el-blog-de-causa-en-comun/trafico-de-armas-una-historia-de-exito/

Editorial Staff. (2019, 8 de octubre). Puso en marcha gobernador Kiko Vega campaña "Las armas, ni de juguete". News Report MX. https://newsreportmx. com/2019/10/08/puso-en-marcha-gobernador-kiko-vega-campana-las-armasni-de-juguete/

Flores, E. (2020, 24 de septiembre). Estalló la guerra, todos a echar bala: la Sedena registró a civiles $120 \%$ más armas entre 2006 y 2019. Sin embargo. https://www. sinembargo.mx/24-09-2020/3860989

France24. (2021, 6 de junio). Luego de 32 años, California permitirá de nuevo el uso de armas de asalto. France 24. https://www.france24.com/es/ee-uu-y-canad\%C3\%A1/20210606-rifles-asalto-california-juez-sentencia

Gervasoni, C. (2011). Una teoría rentística de los regímenes subnacionales: federalismo fiscal, democracia y autoritarismo en las provincias argentinas. Desarrollo Económico, 50(200), 576-610. https://www.jstor.org/stable/pdf/41408182.pdf

Gibson, E. L. (2007). Control de límites: autoritarismo subnacional en países democráticos. Desarrollo Económico, 47(186), 163-191. https://www.jstor.org/stable/pdf/30037145.pdf

González, P. G., Vega, L. M. \& Flores, V. M. (2017). El incremento de la mortalidad por armas de fuego y su relación con el estancamiento de la esperanza de vida en México. Ciência Ẽ Saúde Colectiva, 22(9), 2861-2872. https://doi. org/10.1590/1413-81232017229.21902016

González, R. (2021, 5 de febrero). Aumenta tráfico hormiga de armas de Eu durante pandemia. La Voz de la Frontera. https://www.lavozdelafrontera.com.mx/ mexico/sociedad/aumenta-trafico-hormiga-de-armas-desde-eu-durante-pandemia-sre-delincuencia-organizada-decomisos-6326412.html

Goodwin, Z. (2020, 8 de septiembre). Tráfico de armas a cuentagotas en frontera con EE.UU. desangra a México. Insight Crime. https://es.insightcrime.org/noticias/ analisis/trafico-armas-cuentagotas-mexico-eeuu/

Guardia Estatal de Seguridad e Investigación (GESI). (2021, 20 de febrero). Incidencia delictiva. Estadística estatal y municipal, Años 2013-2020. https:/ / www.seguridadbc. gob.mx/contenidos/estadisticas2.php

Gun Violence Archive (GVA). (2021, 29 de abril). Gun Violence Archive. State Data. California. https://www.gunviolencearchive.org/congress/ca

Henry, G. \& Gordon, C. (2001). Tracking issue attention: specifying the dynamics of the public agenda. The Public Opinion Quarterly, 65(2), 157-177. https://www. jstor.org/stable/3078800

Hernández, G. (2020). Violencia política y el debilitamiento del federalismo mexicano en el proceso electoral 2017-2018. En A. Escamilla Cadena \& L. del Alizal Arriaga (Coords.), La elección federal de 2018 en México: una nueva reconfiguración del poder político (pp. 413-436). Ediciones del lirio. http://148.206.32.30/mydes/ wp-content/uploads/2021/03/Libro_La-elecci\%C3\%B3n-federal-de-2018-enM\%C3\%A9xico_PP-2.pdf 
Imco Staff. (2016, 10 de octubre). Legalizar la portación de armas de fuego, puerta abierta al aumento en la violencia. Instituto Mexicano para la Competitividad, A. C. https:/ / imco.org.mx/legalizar-la-portacion-de-armas-de-fuego-puerta-abierta-al-aumento-en-la-violencia/

Ingram, M. C., Rodríguez Ferreira, O. \& Shirk, D. A. (2011). Justiciabarómetro: Survey of judges, prosecutors, and public defenders in nine Mexican states. Trans-border Institute-University of San Diego. https://justiceinmexico.org/wp-content/uploads/2014/09/2011_JABO.pdf

Institute for Economics \& Peace (IEP). (2020). Índice de paz México 2020: Identificar y medir los factores que impulsan la paz. https://static1.squarespace.com/static/5eaa390ddf0dcb548e9dd5da/t/5eb16bec8506ae2eba951b1d/1588686074573/ESP+MPI+2020+\%28web\%292.pdf

Instituto Nacional de Estadística y Geografía (Inegi). (2019). Anuario estadístico y geográfico por entidad federativa. https://www.inegi.org.mx/contenido/productos/prod_serv/contenidos/espanol/bvinegi/productos/nueva_estruc/AEGPEF_2019/702825192242.pdf

Instituto Nacional de Estadística y Geografía (Inegi). (2020, 23 de septiembre). Datos preliminares revelan que en 2019 se registraron 36 mil 476 homicidios (comunicado de prensa núm. 432/20). https://www.inegi.org.mx/contenidos/saladeprensa/ boletines/2020/EstSociodemo/Defcioneshomicidio2019.pdf

Instituto Nacional de Estadística y Geografía (Inegi). (2021a, 13 de enero). Movimientos migratorios. Baja California. http://cuentame.inegi.org.mx/monografias/informacion/bc/poblacion/m_migratorios.aspx?entidades=Lista+en+orden+alfab\%C3\%A9tico

Instituto Nacional de Estadística y Geografía (Inegi). (2021b). Encuesta Nacional de Seguridad Pública Urbana ENSU primer trimestre 2021. Principales resultados. https:// www.inegi.org.mx/contenidos/programas/ensu/doc/ensu2021_mar_presentacion_ejecutiva.pdf

Lajous, A. \& Piccato P. (2018, 1 de abril). Tendencias históricas del crimen en México. Nexos. https://www.nexos.com.mx/?p=36958

López Ponce, J. (2020, 7 de junio). uif investiga tráfico de armas en aduana de Mexicali. Milenio. https://www.milenio.com/policia/investigan-trafico-de-armas-y-automoviles-en-mexicali

McCombs, M. \& Shaw, D. L. (1972). The agenda-setting function of mass media. Public Opinion Quarterly, 36(2), 176-187. https://www.jstor.org/stable/2747787

McGreevy, P. (2021, 30 de julio). California's long history on assault weapons on the line in court battle. Los Angeles Times. https://www.latimes.com/california/story/2021-07-30/california-long-history-assault-weapon-ban

McGrew, A. G. \& Lewis, P. G. (Eds.). (1992). Global politics: globalization and the Nation-State. Polity press.

Medellín Torres, P. (2004). La política de las políticas públicas: propuestas teórica y metodológica para el estudio de las políticas públicas en países de frágil institucionalidad. Comisión Económica para América Latina y el Caribe, https://www.cepal.org/sites/ default/files/publication/files/6082/S047566_es.pdf

Medina, F. (2020). Radiografía del tráfico ilícito de armas en México. Revista Mexicana de Política Exterior, (número especial), 181-192. https://revistadigital.sre.gob. $\mathrm{mx} /$ images/stories/numeros/ne2020/medinaradiografiarmpene2020.pdf 
Méndez Martínez, J. L. (2015). Análisis de políticas públicas: Teoría y casos. El Colegio de México.

Merino, M. (2016). Políticas públicas. Ensayo sobre la intervención del Estado en la solución de problemas públicos. Centro de Investigación y Docencia Económica.

México Evalúa. (2019). Hallazgos 2019. Seguimiento y evaluación del sistema de justicia penal en México. https://www.mexicoevalua.org/mexicoevalua/wp-content/uploads/2020/10/hallazgos2019-27oct.pdf

Nájar, A. (2019, 20 de agosto). Cómo es el "tráfico hormiga" de armas de EE.UU. a México detrás de la inédita ola de violencia en ese país. BBC. https:/ /www.bbc.com/mundo/ noticias-america-latina-49404229

Notimex. (2019, 22 de junio). Garita de San Ysidro, la más transitada del mundo. El Sol de Tijuana. https://www.elsoldetijuana.com.mx/local/garita-de-san-ysidro-la-mas-transitada-del-mundo-tijuana-mexico-estados-unidos-frontera-3801453.html

Ocampomi. (2021, 7 de septiembre). The Merida Initiative. u.s. Embassy \& Consulates in Mexico. https://mx.usembassy.gov/the-merida-initiative/

Oficina de las Naciones Unidas contra la Droga y el Delito (UNODC). (2020). Estudio mundial sobre el tráfico de armas de fuego 2020. https://www.unodc.org/documents/firearms-protocol/2020/Global_Study_Ex_Summary_es.pdf

Ortega Pérez, N. \& Ruiz Seisdedos, S. (2005). Definición de problemas y diseño de la agenda. En M. Pérez Sánchez (Ed.), Análisis de políticas públicas (pp. 110-130). Universidad de Granada.

Ortega, V. \& Mack, S. (2019, 5 de agosto). Las veces que México ha hecho un llamado al control de armas en EU. El Universal. https://www.eluniversal.com.mx/ nacion/seguridad/las-veces-que-mexico-ha-hecho-un-llamado-al-control-de-armas-en-eu

Osorio, D. (2020, 30 de marzo). Sobre las armas con las que se delinque en México. Nexos. https://seguridad.nexos.com.mx/sobre-las-armas-con-las-que-se-delinque-en-mexico/

Parsons, W. (2007). Políticas públicas. Una introducción a la teoría y la práctica del análisis de políticas públicas. Flacso-México/Miño y Dávila Editores.

Presidencia de la República. (2020). 2 Informe de Gobierno 2019-2020. https://presidente.gob.mx/wp-content/uploads/2020/09/PRESIDENTE\%20AMLO $\% 20$ 2INFORME\%20DE\%20GOBIERNO\%202019-2020.pdf

Redacción/El Vigia. (2019, 4 de diciembre). Destruye la Sedena 742 armas de fuego. El Vigía. https://www.elvigia.net/general/2019/12/4/destruye-la-sedena-742armas-de-fuego-339980.html

Rojas Aravena, F. (2008). Mayor presencia del crimen organizado: consecuencia de las crisis de gobernabilidad y el débil imperio de la ley. En L. G. Solís \& F. Rojas Aravena (Eds.), Crimen organizado en América Latina y el Caribe (pp. 95-107). Secretaría General-Flacso. https://biblio.flacsoandes.edu.ec/catalog/resGet. php?resId $=42584$

Salinas Maldonado, C. (2020, 19 de enero). El tiroteo en una escuela de México revela una historia familiar criminal. El Pais. https://elpais.com/internacional/2020/01/19/mexico/1579451425_958231.html 
Sánchez, E. (2019, 22 de octubre). México y EU lanzan operativo "Frozen" contra tráfico de armas. Excélsior. https://www.excelsior.com.mx/nacional/mexico-y -eu-lanzan-operativo-frozen-contra-trafico-de-armas/1343201

Secretaría de la Defensa Nacional (Sedena). (2014a). Hoja de respuesta a solicitudes de información. 27 de marzo de 2014. Número de Folio 0000700030314.

Secretaría de la Defensa Nacional (Sedena). (2014b). Hoja de respuesta a solicitudes de información. 24 de febrero de 2014. Número de Folio 0000700026614.

Secretariado Ejecutivo del Sistema Nacional de Seguridad Pública (sEsnsP). (2021). Incidencia delictiva del fuero común 2020. https:/ / drive.google.com/file/d/1qwOWT4T9_80wgVAF0fc_QokWQKixAoK/view

Seguridad Justicia y Paz. (2021, 20 de abril). Boletin Ranking de las 50 ciudades más violentas del mundo 2020. http://www.seguridadjusticiaypaz.org.mx/sala-de-prensa/1596boletin-ranking-de-las-50-ciudades-ma-s-violentas-del-mundo-2020

Semple, K. (2020, 31 de enero). Más violencia, menos reos: la reforma judicial de México. The New York Times. https://www.nytimes.com/es/2020/01/31/espanol/america-latina/reforma-judicial-mexico.html

Tamayo, M. \& Carrillo Barroso, E. (2005). La formación de la agenda. Foro Internacional, 45(4), 658-681. https://forointernacional.colmex.mx/index.php/fi/ article/view/1785

U.s. Department of Justice. (2012). A review of ATF's Operation Fast and Furious and related matters. https://oig.justice.gov/reports/2012/s1209.pdf

Gerardo Hernández

Mexicano. Doctor en estudios sociales, línea procesos políticos por la Universidad Autónoma Metropolitana, Unidad Iztapalapa. Actualmente es investigador del Instituto de Investigaciones Sociales de la Universidad Autónoma de Baja California. Líneas de investigación: seguridad pública, políticas públicas e instituciones políticas. Publicación reciente: Hernández, G. (2020). Inseguridad y poder político en el Triángulo Norte de Centroamérica. Perfiles Latinoamericanos, 28(55), 143-169. https:/ / doi.org/10.18504/pl2855-006-2020

Zulia Orozco Reynoso

Mexicana. Doctora en urbanismo, línea política y sociología urbana aplicada al ordenamiento territorial por la Universidad Nacional Autónoma de México. Actualmente es investigadora en el Instituto de Investigaciones Sociales de la Universidad Autónoma de Baja California. Líneas de investigación: seguridad pública, tecnología y seguridad, y desarrollo urbano. Publicación reciente: Orozco, Z. (2020). Agenda de seguridad: los retos presentes en Baja California. En G. Hernández, I. López Sandoval, E. O. Villegas Olivar \& M. P. Olmeda García (Coords.), Problemas de la agenda pública en Baja California (pp. 95-111). UABC. 